\title{
Predictors Of Performance In An Online Financial Management Simulation
}

\author{
Thomas Willey, Grand Valley State University \\ Susan Edwards, Grand Valley State University \\ Vijay Gondhalekar, Grand Valley State University
}

\begin{abstract}
The purpose of our research is to investigate the factors that impact performance in a financial management simulation component of a second financial management class. We measured the impact of previous course performance, gender, age and other concurrent course components on the dependent variable. Using two different statistical techniques, we found that a student's current scores on exams, case write-ups and written summary reports were the strongest predictors of performance in the online simulation. The predictive ability of this variable was complemented by the positive impact of a student's age. All else equal, the higher the age, the better the performance as measured by the simulated firm's stock price. These results are encouraging and we will continue this experiential process during future semesters to add additional students to our sample size to further investigate the relationship between performance in the simulation and student characteristics.
\end{abstract}

Keywords: simulation pedagogy; managerial effectiveness; performance predictors; experiential learning

\section{INTRODUCTION AND BACKGROUND}

$\mathrm{n}$ a recent publication of the AACSB, Bisoux (2007) states "B-schools are getting serious about games that offer students real-time lessons in leadership, globalization, ethics and other complex issues that cannot be captured in a textbook." Students from over five hundred schools use one or more of the three business simulations, Foundation, Capstone or COMP-XM, provided by an AACSB member firm in Northfield, Illinois (www.capsim.com). Fortunately for finance instructors, there are many simulation choices to implement in their various teaching assignments. In bank management classes, the Stanford Bank Game is widely used to illustrate the financial interrelationships within a financial institution (http://www.hrwinc.com/sbgmenu.htm). In investments, instructors may use Stock-Trak, an online portfolio simulation that enables students to manage a hypothetical $\$ 500 \mathrm{~K}$ portfolio, using real world assets in their buy and sell decisions (www.stocktrak.com). In corporate finance courses, the FinGame ONLINE 4.0, The Financial Management Decision Game (Brooks, 2004) is a popular vehicle for students to investigate the interrelationships between financial management, financial accounting, marketing and production management (www.mhhe.com/fingame4). This type of learning, known as experiential learning, is a valuable tool for business educators.

Felton, Gibson and Sanbonmatsu (2004) used the Stock-Trak simulation to evaluate the roles gender and optimism play on the riskiness of student's investment choices. Their results indicated males, specifically more optimistic males, made riskier investment choices than females. Mitchell (2004) compared the performance of one group of students in a computer based simulation with some management cases versus a second group of students who relied solely on case discussion. His results did not indicate any statistically significant different in any of the learning outcomes. A classroom application of this specific online corporate finance exercise was found in an article by Clark, Gjerde and Skinner (2003). These authors used the financial management simulation to measure the impact of team teaching interventions on the performances of an experimental group and a control group. The purpose of this research is to investigate the factors that impact performance in the simulation component of a second advanced financial management class. 


\section{METHODS AND HYPOTHESES}

Our primary hypothesis is that higher (lower) accumulated wealth in the simulation will be positively (negatively) related to a student's grade in the prerequisite first financial management course, age and the remaining concurrent course components (exams, case write-ups and written summary reports). We have no a priori expectation for the gender variable in the analysis. Our secondary and related hypothesis will be tested by first separating the sample into two groups: high performers and low performers. High performers are defined as students who achieved a score of greater than $90 \%$ in the simulation. Otherwise, a student would be classified in the second group. Our second hypothesis is that the above predictor variables would more accurately explain variability in performance of the first group, relative to the second group.

The internet-based financial simulation used in the study is a multi-period corporate financial simulation, where students have control of the essential financial and operating decisions of their firm. These decisions expose the students to the interlocking relationships between financial management, accounting, production management and marketing. For twelve weeks each semester, twenty potential decisions are required for the simulation. Students may run unlimited pro-forma, or what-if, analyses prior to their submission of their actual decisions on the website. Once the actual quarter has been run, a student gets immediate feedback on her or his decisions and performance through the stock price. The stock price, along with all of the dividends paid, is the performance component in a student's grade.

\begin{tabular}{|l|c|c|c|}
\hline \multicolumn{4}{|c|}{ Table 1: Descriptive Statistics for the Variables } \\
\hline \multicolumn{1}{|c|}{ Winter 2004 } & Mean & SD & Median \\
\hline Sample Size (M) & & NA & NA \\
\hline Sample Size (F) & 33 & NA & NA \\
\hline PERFORMANCE & 17 & 5.58 & 87.50 \\
\hline FM1 & 87.88 & 0.73 & 3.30 \\
\hline GENDER & 3.15 & NA & NA \\
\hline AGE & 0.34 & 6.38 & 23.00 \\
\hline COMPOSITE & 25.5 & 4.23 & \\
\hline \multicolumn{1}{|c|}{ Fall 2004 } & 87.63 & & NA \\
\hline Sample Size (M) & & NA & NA \\
\hline Sample Size (F) & 30 & NA & 87.00 \\
\hline PERFORMANCE & 24 & 5.89 & 3.00 \\
\hline FM1 & 87.94 & 0.68 & NA \\
\hline GENDER & 2.95 & NA & 23.00 \\
\hline AGE & 0.44 & 2.99 & 89.50 \\
\hline COMPOSITE & 23.8 & 3.82 & NA \\
\hline \multicolumn{1}{|c|}{ Winter 2005 } & 88.76 & & NA \\
\hline Sample Size (M) & & NA & 88.00 \\
\hline Sample Size (F) & 30 & NA & NA \\
\hline PERFORMANCE & 15 & 5.29 & 23.00 \\
\hline FM1 & 88.31 & 0.62 & 86.69 \\
\hline GENDER & 3.11 & NA & \\
\hline AGE & 0.33 & 3.36 & NA \\
\hline COMPOSITE & 24.1 & 3.67 & NA \\
\hline \multicolumn{1}{|c|}{ Fall 2005 } & 87.01 & & 88.00 \\
\hline Sample Size (M) & & NA & NA \\
\hline Sample Size (F) & 39 & NA & 23.00 \\
\hline PERFORMANCE & 26 & 5.50 & 86.33 \\
\hline FM1 & 88.12 & 0.77 & NA \\
\hline GENDER & 3.07 & 2.76 & \\
\hline AGE & 0.40 & 4.71 & \\
\hline COMPOSITE & 23.5 & & \\
\hline & 86.77 & & \\
\hline
\end{tabular}


Variable definitions: PERFORMANCE is the points awarded for the student's relative performance in the simulation. FM1 is the student's performance in the prerequisite upper-level financial management course (on a 4.0 scale). GENDER is an indicator variable equal to one for female students and zero for male students. AGE is the student's age in years while enrolled in the class. COMPOSITE is the composite grade on all other course components. NA is not applicable; SD is the sample standard deviation. The sample size equals 214 students.

The study consists of two hundred and fourteen students enrolled in ten sections of their required second upper-level financial management course at a regional university in the Midwest. The same instructor taught two sections during the Winter 2004, three sections in the Fall 2004 semester, two sections in the Winter 2005 semester and three sections in the Fall 2005 semester. Texts, cases, handout materials and the coverage were the same between all of the classes. Each of the students ran their own individual company in the required simulation. The composition and demographics of the students in the ten sections, taught over the four semesters of our study, are very similar. The average (median) age was 24.3 (23) years old and the average (median) pre-requisite course GPA was 3.07 (3.00) on a four point scale. The summary statistics for the variables for each semester are contained in Table 1.

Additional analysis supports the hypothesis that the student characteristics are homogeneous. Based on a semester by semester breakdown, fifteen of the eighteen pair-wise comparisons supported the null hypothesis of no difference between the student groups. Statistically significant differences were found in the composite scores for two of the semester comparisons. The results, contained in Table 2, were based on both parametric and nonparametric methods. As an overall finding, the characteristics of the ten sections were very similar.

\begin{tabular}{|c|c|c|c|c|}
\hline \multicolumn{5}{|c|}{$\begin{array}{c}\text { Table } 2 \\
\text { Results of independent samples } T \text {-test and Mann-Whitney } U \text {-test; } \\
\text { Winter } 2004 \text { versus Fall } 2004 \text { versus Winter } 2005 \text { versus Fall } 2005\end{array}$} \\
\hline & $T$-statistic & $\begin{array}{l}\text { Significance } \\
\text { (two-tailed) }\end{array}$ & $W$-statistic & $\begin{array}{l}\text { Significance } \\
\text { (two-tailed) }\end{array}$ \\
\hline \multicolumn{5}{|c|}{ Winter 2004 versus Fall 2004} \\
\hline FM1 & 1.44 & $(0.15)$ & 2,882 & $(0.09)$ \\
\hline AGE & 1.76 & $(0.08)$ & 2,895 & $(0.07)$ \\
\hline COMP & -1.42 & $(0.16)$ & 2,422 & $(0.19)$ \\
\hline \multicolumn{5}{|c|}{ Winter 2004 versus Winter 2005} \\
\hline FM1 & 0.37 & $(0.71)$ & 2,502 & $(0.45)$ \\
\hline AGE & 1.37 & $(0.18)$ & 2,527 & $(0.33)$ \\
\hline COMP & 0.77 & $(0.44)$ & 2,564 & $(0.22)$ \\
\hline \multicolumn{5}{|c|}{ Winter 2004 versus Fall 2005} \\
\hline FM1 & 0.63 & $(0.53)$ & 3,021 & $(0.49)$ \\
\hline AGE & 2.11 & $(0.04)$ & 3,247 & $(0.05)$ \\
\hline COMP & 1.03 & $(0.31)$ & 3,101 & $(0.26)$ \\
\hline \multicolumn{5}{|c|}{ Fall 2004 versus Winter 2005} \\
\hline FM1 & -1.13 & $(0.26)$ & 2,542 & $(0.26)$ \\
\hline AGE & -0.51 & $(0.61)$ & 2,570 & $(0.35)$ \\
\hline COMP & 2.32 & $(0.02)$ & 3,046 & $(0.02)$ \\
\hline \multicolumn{5}{|c|}{ Fall 2004 versus Fall 2005} \\
\hline FM1 & -0.85 & $(0.40)$ & 3,076 & $(0.38)$ \\
\hline AGE & 0.56 & $(0.58)$ & 3,281 & $(0.83)$ \\
\hline COMP & 2.54 & $(0.01)$ & 3,698 & $(0.01)$ \\
\hline \multicolumn{5}{|c|}{ Winter 2005 versus Fall 2005} \\
\hline FM1 & 0.27 & $(0.79)$ & 2,504 & $(0.97)$ \\
\hline AGE & 1.03 & $(0.31)$ & 2,679 & $(0.26)$ \\
\hline COMP & 0.29 & $(0.77)$ & 2,546 & $(0.77)$ \\
\hline
\end{tabular}

Variable definitions: FM1 is the student's performance in the prerequisite upper-level financial management course (on a 4.0 scale). GENDER is an indicator variable equal to one for female students and zero for male students. AGE is the student's age in years while enrolled in the class. COMPOSITE is the composite grade on all other 
course components. The sample size equals 214 students.

The pooled data was initially analyzed using ordinary least squares regression (OLS). The estimated equation was:

PERFORMANCE $=$ CONSTANT + FM1 + GENDER + AGE + COMPOSITE + ERROR $(1)$

where:

PERFORMANCE (PERF) is the points awarded for the student's relative performance on the FinGame simulation; FM1 is the student's grade in the prerequisite upper-level financial management course;

GENDER (GEND) is an indicator variable equal to one if female, zero if male;

AGE is the student's chronological age, a proxy for work experience;

COMPOSITE (COMP) is the student's composite grade on all other course components (two exams, four case write-ups and two written simulation summary reports) and

ERROR is the unexplained component of the student's performance.

Further analysis of the pooled data was done using binary logistic regression. The estimated equation was:

PERD $=$ CONSTANT + FM1 + GENDER + AGE + COMPOSITE + ERROR (2)

where:

PERD is the relative performance measure on the FinGame simulation. This value is a binary variable equal to one if student achieved a $90 \%$ to $100 \%$; otherwise, equal to zero; and the remaining variables are as discussed in the first equation.

\section{RESULTS AND ANALYSIS}

A correlation analysis of the independent variables is contained in Table 3. The strongest linear relationship exists between the composite score (COMP) and the student's grade in the required first financial management course (FM1) (+0.447). This result indicates the positive relationship between strong performance in the earlier course and academic performance in the subject course. (An analysis using student's pre-course grade point average (GPA) is available on request from the authors.) A statistically significant negative relationship was found between age and composite score $(-0.167)$ which shows that traditional students may perform at a higher level than non-traditional students in the non-simulation components of the course.

\begin{tabular}{|l|c|c|c|}
\hline \multicolumn{4}{|c|}{ Table 3: Pearson's correlation matrix } \\
\hline & FM1 & AGE & GEND \\
\hline AGE & -0.152 & & \\
& $(0.026)$ & 0.057 & \\
\hline GEND & 0.005 & $(0.410)$ & -0.009 \\
& $(0.937)$ & -0.167 & $(0.894)$ \\
\hline
\end{tabular}

Variable definitions: FM1 is the student's performance in the prerequisite upper-level financial management course (on a 4.0 scale). GENDER is an indicator variable equal to one for female students and zero for male students. AGE is the student's age in years while enrolled in the class. COMPOSITE is the composite grade on all other course components. The sample size equals 214 students. $P$-values are in parentheses. 
OLS results are presented in Table 4. In the first estimate, a student's performance in the first financial management class had a positive and statistically significant impact on performance in the simulation $(\mathrm{p}$-value $=$ 0.02). The two independent variables explained approximately two percent of the performance, leaving ninety-eight percent of the results due to other components. The second model improved on our attempts to predict success in the computer exercise. Both of the independent variables of age and composite course scores were statistically significant and positively related to performance (p-values of 0.03 and 0.01 , respectively). The explanatory power of this model increased to $10.5 \%$, relative to Model 1's $1.9 \%$, a change of $453 \%$. The final combined model did not indicate any improvement from the second model. A linear relationship was found, as evidenced by the F-statistic of 6.93 (p-value of 0.01), both age and composite variables were positive and significant and ten percent of the variability in performance was explained by changes in the independent variables.

\begin{tabular}{|c|c|c|c|}
\hline $\begin{array}{l}\text { Ordinary le } \\
\text { Model (1): PERF = } \\
\text { Model (2): PERF = } \\
\text { Model (3): PERF = }\end{array}$ & $\begin{array}{l}\text { estimate } \\
\text { ENDER } \\
\text { OMPOSI } \\
\text { ENDER }\end{array}$ & d (3) on St & ce (PERF) \\
\hline Variable & Model 1 & Model 2 & Model 3 \\
\hline CONSTANT & $\begin{array}{c}84.25 \\
(0.001) \\
\end{array}$ & $\begin{array}{c}45.46 \\
(0.001) \\
\end{array}$ & $\begin{array}{c}46.67 \\
(0.001) \\
\end{array}$ \\
\hline FM1 & $\begin{array}{c}1.29 \\
(0.016)\end{array}$ & & $\begin{array}{c}0.38 \\
(0.510)\end{array}$ \\
\hline GENDER & $\begin{array}{c}-0.39 \\
(0.618)\end{array}$ & & $\begin{array}{c}-0.44 \\
(0.55)\end{array}$ \\
\hline AGE & & $\begin{array}{c}0.19 \\
(0.034)\end{array}$ & $\begin{array}{c}0.19 \\
(0.029)\end{array}$ \\
\hline COMP & & $\begin{array}{c}0.43 \\
(0.001) \\
\end{array}$ & $\begin{array}{c}0.41 \\
(0.001)\end{array}$ \\
\hline$F$-statistic & $\begin{array}{c}3.06 \\
(0.049) \\
\end{array}$ & $\begin{array}{c}13.56 \\
(0.001)\end{array}$ & $\begin{array}{c}6.93 \\
(0.001)\end{array}$ \\
\hline Adjusted $R^{2}$ & $1.9 \%$ & $10.5 \%$ & $10 \%$ \\
\hline
\end{tabular}

Variable definitions: PERF is the points awarded for the student's relative performance in the simulation. FM1 is the student's performance in the prerequisite upper-level financial management course (on a 4.0 scale). GENDER is an indicator variable equal to one for female students and zero for male students. AGE is the student's age in years while enrolled in the class. COMPOSITE is the composite grade on all other course components. $P$-values are in parentheses. The sample size equals 214 students.

Table 5 contains our results from the binary logistic estimation. In this technique, we partitioned the simulation performance into two groups, high and low. High performers are students that earned a relative score of $90 \%$ or higher (79 or $37 \%$ of students are in this group), while the low performance group contains all of the remaining students (135 or $63 \%$ of students). In Model 1, none of the independent variables were statistically significant at $\mathrm{p}$-values less than seven percent. Results for the hypothesis test that all of the coefficients for the predictors are equal to zero was significant with a p-value of 8.6 percent. The Pearson Test is used to measure goodness-of-fit with a null hypothesis of an adequate fit of the model to the data. The results indicate that the null should not be rejected with a probability of eleven percent. Our fourth set of results for the initial model measured the predictive ability using concordant and discordant pairs. A concordant pair is defined as a student with high (low) performance having a higher probability of having high (low) performance, a discordant pair is just the opposite and the pair is categorized as a tie if the probabilities are equal. This model correctly predicted $55 \%$ of the concordant pairs.

Our results from the second model under this technique were very similar to our findings under the initial OLS regression. The single most important factor in predicting performance in the simulation was a student's 
composite score in the course (p-value $=0.01$ ). Similarly, the higher (lower) the student's age, the better (worse) the relative performance should be. The null hypothesis that all of the slopes of the independent variables are equal to zero is rejected and the null hypothesis of an adequate fit of the model is retained, as long as alpha is less than 0.503. The predictive ability of the second model increased by approximately eighteen percent, or from 55\% to $65 \%$ in absolute terms, relative to the previously discussed Model 1 results.

Our composite model that uses all four predictor variables is the last of our empirical results. The statistical significance of the age variable increased and the strong predictive ability of the composite variable is remains. As discussed in Model 2, the $G$-statistic of 19.44 (p-value of 0.01) indicates the null hypothesis of all slopes being equal to zero should be rejected. The Pearson Goodness-of-Fit and Measures of Association tests support our previous findings for the second model. Specifically, a marginal increase in the predictive ability of the model (from $65 \%$ to $67 \%$ ) and a decrease in the Pearson test, since the p-value changed from 0.503 to 0.373 .

\begin{tabular}{|c|c|c|c|}
\hline \multicolumn{4}{|c|}{$\begin{array}{l}\text { Table } 5 \\
\text { Binary logistic regression estimates of Models (1), (2) and (3) on Student's Performance (PERD) } \\
\text { Model (1): PERD = Constant + FM1 + GENDER } \\
\text { Model (2): PERD = Constant + AGE + COMPOSITE } \\
\text { Model (3): PERD = Constant + FM1 + GENDER + AGE + COMPOSITE }\end{array}$} \\
\hline Variable & Model 1 & Model 2 & Model 3 \\
\hline CONSTANT & $\begin{array}{c}-1.56 \\
(0.021)\end{array}$ & $\begin{array}{c}-15.12 \\
(0.001)\end{array}$ & $\begin{array}{l}-15.10 \\
(0.001)\end{array}$ \\
\hline FM1 & $\begin{array}{c}0.38 \\
(0.072) \\
\end{array}$ & & $\begin{array}{c}0.09 \\
(0.696) \\
\end{array}$ \\
\hline GENDER & $\begin{array}{c}-0.37 \\
(0.213)\end{array}$ & & $\begin{array}{c}-0.45 \\
(0.146)\end{array}$ \\
\hline AGE & & $\begin{array}{c}0.08 \\
(0.047) \\
\end{array}$ & $\begin{array}{c}0.09 \\
(0.034) \\
\end{array}$ \\
\hline COMP & & $\begin{array}{c}0.14 \\
(0.001) \\
\end{array}$ & $\begin{array}{c}0.14 \\
(0.001) \\
\end{array}$ \\
\hline Test that all slopes are zero: $G$-statistic & $\begin{array}{c}4.91 \\
(0.086)\end{array}$ & $\begin{array}{c}17.12 \\
(0.001)\end{array}$ & $\begin{array}{c}19.44 \\
(0.001)\end{array}$ \\
\hline Goodness-of-Fit: Pearson's Chi Square & $\begin{array}{c}21.93 \\
(0.110) \\
\end{array}$ & $\begin{array}{c}197.19 \\
(0.503) \\
\end{array}$ & $\begin{array}{l}215.03 \\
(0.373) \\
\end{array}$ \\
\hline \multicolumn{4}{|l|}{ Measures of Association: } \\
\hline Concordant Pairs (\%) & 55.1 & 65.0 & 66.6 \\
\hline Discordant Pairs (\%) & 34.8 & 34.3 & 32.8 \\
\hline Ties (\%) & 10.0 & 0.70 & 0.60 \\
\hline
\end{tabular}

Variable definitions: PERD is an indicator variable equal to one if the simulation performance is greater than $90 \%$ and otherwise, equal to zero. FM1 is the student's performance in the prerequisite upper-level financial management course (on a 4.0 scale). GENDER is an indicator variable equal to one for female students and zero for male students. AGE is the student's age in years while enrolled in the class. COMPOSITE is the composite grade on all other course components. $P$-values are in parentheses. The sample size equals 214 students.

\section{DISCUSSION AND CONCLUDING REMARKS}

The purpose of our research is to investigate the factors that impact performance in a financial management simulation component of a second financial management class. We measured the impact of previous course performance, gender, age and other concurrent course components on the dependent variable. Using two different statistical techniques, we found that a student's current scores on exams, case write-ups and written summary reports were the strongest predictors of performance in the online simulation. The predictive ability of this variable was complemented by the positive impact of a student's age. All else equal, the higher the age, the better the performance, as measured by the simulated firm's stock price. Older students are more likely to have relevant work 
experience that could lead to better relative performance. Another interesting outcome is the relationship between the student's grade in the prior financial management course and performance. This variable was not statistically significant in two of the three attempts to predict success or failure of the firm. Since the first course is a prerequisite to the second course, the validity of this particular course sequencing is suspicious. The gender variable had no impact on the performance in the simulation. However, changes in learning and ability may be difficult to measure with a high degree of accuracy and if the benefits for the student exceed the costs, the implementation of a supplemental teaching resource is valid. These results are encouraging and we will continue this experiential process during future semesters to add additional students to our sample size to further investigate the relationship between performance in the simulation and student characteristics.

\section{REFERENCES}

1. Bisoux, T. (2007). B-schools got game. BizEd, (May/June), 38-43.

2. Brooks, L. D. (2004). FINGAME ONLINE 4.0, The Financial Management Decision Game. McGraw-Hill (1221 Avenue of the Americas, New York, NY 10020, USA).

3. Clark, R. A., Gjerde, K. A. P. and Skinner, D. (2003). The effects of interdisciplinary instruction on simulation performance. Simulation and Gaming, 34(1), 150-163.

4. Felton, J., Gibson, B. and Sanbonmatsu, D. M. (2004). Preference for risk in investing as a function of trait optimism and gender. The Journal of Behavioral Finance, 4(1), 33-40.

5. Management Simulations, Incorporated. (2007). Foundation Business Simulation, Northfield, IL.

6. Mitchell, R. C. (2004). Combining cases and computer simulations in strategic management courses. Journal of Education for Business, 79(4), 198-204.

7. Stanford Bank Game. (2005). Human Resources West, Incorporated, San Francisco, CA. 


\section{NOTES}

